\title{
Application of Lasers in Treatment of Oral Premalignant Lesions
}

\author{
Amaninder Singh ${ }^{* 1}$, Akanksha Zutshi ${ }^{2}$, Preetkanwal Singh Ahluwalia ${ }^{3}$, Vikas Sharma ${ }^{4}$ and Vandana Razdan ${ }^{5}$ \\ 1,4oral and maxillofacial surgery, reader, National Dental College and Hospital, Dera Bassi, Punjab \\ ${ }^{2}$ oral and maxillofacial surgery, senior lecturer, National Dental College and Hospital, Dera Bassi, Punjab \\ ${ }^{3}$ oral and maxillofacial surgery, professor, National Dental College and Hospital, Dera Bassi, Punjab \\ ${ }^{5}$ Pharmacology, professor, Govt. Medical College and Hospital, Jammu
}

Received: April 03, 2018; Accepted: June 04, 2018; Published: June 11, 2018

*Corresponding author: Amaninder Singh, House No- 620, Phase- 6, mohali, 160055, E-mail address: drsinghaman28@gmail.com

\begin{abstract}
Laser systems and their application in dentistry and especially oral surgery are rapidly improving today. Lasers are being used as a niche tool as direct replacement for conventional approaches like scalpel, blades, electro surgery, dental hand piece. The specific advantages of lasers are incision of tissues, coagulation during operation and postoperative benefits like low postoperative pain, better wound healing. For soft tissue oral surgical procedures lasers can be used for treatment of conditions such as premalignant lesions, frenectomy, epulis fissuratum, fibroma, vascular lesions, excision of exophytic lesions etc.
\end{abstract}

Key words: Laser; premalignant lesions; electro surgery; coagulation

\section{Introduction}

The word laser is an acronym for Light Amplification by Stimulated Emission of Radiation. Laser energy released is based on the concept of Albert Einstein (1917) quantum theory of stimulated emission [1]. In 1960, Theodore Maiman demonstrated the first practical laser by exciting ruby rod with intense pulses of light by flash lamp [2]. In 1964 Patel developed $\mathrm{CO}_{2}$ gas laser, the first laser used in oral and maxillofacial surgery [3]. Use of laser system in dentistry is rapidly improving. Lasers are being used as a niche tool as direct replacement for conventional approaches like scalpel, blades, electro surgery, dental hand piece. The specific advantages of lasers are incision of tissues, coagulation during operation and postoperative benefits like low postoperative pain, better wound healing and reduced cicatrization[4]. Reduction in the number of myofibroblasts and eosinophils on the wound surface during the healing process after laser surgery is thought to be associated with reduced scar formation.

Lasers emit coherent, monochromatic and collimated electromagnetic radiation with high intensity and thus can deposit a lot of energy within a small area and are considered better than other light sources [5]. Lasers can be divided on the basis of energy of the beam and wavelength of the emitted radiation.

Classification of lasers [6]

\begin{tabular}{|c|c|}
\hline \multirow{2}{*}{ Gas lasers } & Argon \\
\cline { 2 - 2 } & $\mathrm{CO}_{2}$ \\
\hline \multirow{2}{*}{ Liquid } & Dyes \\
\hline \multirow{2}{*}{ Solid } & Nd:YAG \\
\hline \multirow{2}{*}{ Semi conductor } & Diode \\
\hline \multirow{2}{*}{ Excimers } & Er:YAG \\
\hline & Silicone lasers \\
\hline & Argon-F \\
\hline
\end{tabular}

The most common surgical lasers emit wavelength in infrared part of the spectrum Nd: YAG $(\lambda=10,064)$; Er:YAG $(\lambda=2.94)$ and $\mathrm{CO}_{2}$ laser $(\lambda=10.6)$. In visible spectrum, argon laser emit light between $458-515 \mathrm{~nm}$ and excimer lasers are located in U.V part of spectrum (100-400nm).

Diode lasers emit wavelength $810-980 \mathrm{~nm}$ in a continuous or pulse mode and can be used as a possible modality for soft tissue surgical procedures in oral cavity [7].

Oral premalignant lesions of the oral cavity such as leukoplakia and erythroplakia remain a diagnostic and treatment challenge as they have a potential for malignant transformation. Such lesions may harbor histological changes such as squamous hyperplasia, mild dysplasia, moderate dysplasia, severe dysplasia, and carcinoma in-situ. Patients with this condition experience a 50-60-fold greater risk of developing oral cancer than the remainder of the population. Various treatment modalities have been described for oral premalignant lesions. They can broadly be divided into surgical and nonsurgical treatments. The nonsurgical treatments include photodynamic therapy and topical or systemic medical treatment using carotenoids, retinoids, bleomycin, etc. There are different kinds of surgical treatment 
for these lesions including scalpel excision, electro cautery, cryosurgery, laser surgery. The gold standard for management of the clinically evident high-grade premalignant disease is excision or laser ablation. The importance of using laser for biopsy and vaporization of extensive, diffuse mucosal lesions lie in the incomparable speed, efficacy and overall tolerability as compared to other surgical modalities. The mucosa of entire oral cavity can be vaporized without significant patient morbidity and major problem in feeding and hydration. However, moderate and lowgrade pre-malignancy may be treated with observation as well as ablation.

Lesions of the oral mucosa can be removed by ablation or vaporization procedures. Lasers transmit energy to the cells causing warming, coagulation (above 1000C), protein denaturation, vaporization and carbonization [8]. The main advantage of using diode lasers are minimal postoperative swelling, improved wound healing and decreased postoperative pain, it offers bloodless surgical field with minimal trauma to tissue [9]. The mechanism responsible for the effect of laser is the ability of laser photons to alter cellular metabolism after its absorption by cytochrome $\mathrm{C}$ oxidase. As a result ATP release is increased and this causes increased function of cells that are poorly perfumed or intoxicated [10].

$\mathrm{CO}_{2}$ lasers produce a beam of infrared light having wavelength $10,600 \mathrm{~nm}$ and is well absorbed by water. This wavelength provides ease of cutting and coagulation of soft tissue thereby providing clean operating field but has got limited depth penetration [11].

Diode lasers are manufactured from solid semi-conductor made from combination of aluminium or indium gallium and arsenic. They penetrate deep into mucosa and attenuated by pigmented tissue. These are excellent soft tissue surgical lasers [12]. Diode lasers seem to be of increasing interest in surgical field. For soft tissue oral surgery, diode lasers can be used for treatment of oral leukoplakia, erythroplakia, oral submucous fibrosis, frenectomy, epulis fissuratum, fibroma, vascular lesions, excision of exophytic lesions etc. [13].

Darcangelo et, al. compared diode lasers vs. conventional scalpel and concluded that diode lasers offer numerous advantages as compared to conventional scalpel like lower intraoperative bleeding, lower swelling of the area, better coagulation and no scarring, no need for sutures, reduction of surgical time and lesser postoperative pain [14].

\section{Laser Treatment of Oral Premalignant Lesions}

Oral leukoplakia: According to World Health Organization 2005, oral leukoplakia can be defined as "a white plaque of questionable risk having excluded (other) known diseases or disorders that carry no increased risk for cancer. It is the most common premalignant lesion of the oral cavity. It can be treated by both surgical and non-surgical methods. Non-surgical methods include topical or systemic medical treatment using carotenoids, retinoids, bleomycin, etc. but have less chances of complete recovery. Diode lasers have become the choice of treatment for excision of such lesions. Diode lasers have been used mainly because of its ability to decontaminate and bactericidal property which is responsible for lesser pain and lesser inflammatory signs, for example, swelling and postoperative analgesia.

Vatsal et, al. studied the effect of diode laser in management of oral leukoplakia and found less postoperative pain and no recurrence in 1 year of follow up period [15].

Kharadi et al. evaluated the safety, convenience and effectiveness of $940 \mathrm{~nm}$ diode laser for treatment of homogenous leukoplakia and concluded that healing was perfect without any complication and diode lasers can be used as a better treatment modality [16].

Dragana et, al. compared diode laser and conventional scalpel surgery for surgical treatment of oral soft lesions and found that patients treated with laser had significantly lower scores of oedema, hematoma and pain as compared to scalpel group [17].

Sarkar et al. compared efficacy of diode lasers and Er:YAG laser in treating oral leukoplakia and concluded that diode lasers (940nm) was superior to Er:YSG $(2780 \mathrm{~nm})$ as with diode laser there was minimal pain, excellent hemostasis and good wound healing with no postoperative complications [18].

Madukar et, al. evaluated three surgical treatment modalitiescryosurgery, diode lasers and $\mathrm{Co}_{2}$ lasers for treatment of oral leukoplakia and found that laser therapy offered better clinical results than cryotherapy and absence of scar formation at the wound site [19].

Fahim et, al. evaluated the efficacy of lasers in the management of oral premalignant lesions like leukoplakia, erythroplakia, sub mucous fibrosis and concluded that laser therapy is effective in overall management of oral premalignant lesions [20].

Sarkar et, al. compared the effectiveness of diode laser and Er:YSG laser in treating oral leukoplakia and found that diode lasers caused no pain, excellent hemostasis and better wound healing with no postoperative complications.

Ishii et, al. concluded that healing of premalignant lesions like leukoplakia after laser surgery is satisfactory with lesser chances of recurrence rate [21].

Singh et, al. conducted a study on treatment of oral leukoplakia with $\mathrm{CO}_{2}$ laser vaporization and found only $9.10 \%$ recurrence and $2.27 \%$ malignant transformation with satisfactory wound healing [22].

Horch et, al. conducted a study for treatment of precancerous lesions- 50 patients of leukoplakia, 7 patients of lichen planus and carcinoma in situ with $\mathrm{CO}_{2}$ lasers and followed up for 37 months suggesting that laser therapy can be considered as better treatment modality with satisfactory outcomes [23].

Roodenburg et, al. conducted a study in 70 patients with 103 oral leukoplakia treated by $\mathrm{CO}_{2}$ laser vaporization and found excellent wound healing without scarring and showing a cure rate of $90 \%$. Alfonso et, al. evaluated 65 patients with oral leukoplakia treated with $\mathrm{CO}_{2}$ laser vaporization with main site at 
tongue and followed up for 15 months showing recurrence rate of $35.3 \%$ only $[24,25]$.

Jeryes et, al. also conducted a study on patients having leukoplakia treated with $\mathrm{CO}_{2}$ lasers and found a recurrence rate of $19.9 \%$ [26].

Del Corso et, al. compared $\mathrm{CO}_{2}$ and Nd:YAG lasers for the management of oral leukoplakia and found $\mathrm{CO}_{2}$ laser excision resulted in better outcome than Nd:YAG laser vaporization [27].

Romanos et, al. suggested diode lasers can be used for treating soft tissue tumors, gingival hyperplasia, frenectomies, removal of hemangiomas, vestibuloplasty and peri-implant surgeries [28].

Monteiro et, al. considered $\mathrm{CO}_{2}$ lasers as the gold standard for epulis fissaratum excision due to its speed, but due to its cost being superior to diode laser and limited depth penetration, it makes its application difficult in clinical practice [29].

Pick et, al. used $\mathrm{CO}_{2}$ lasers for treatment of gingival hyperplasia, benign and malignant lesions, bleeding and coagulation disorders and found $\mathrm{CO}_{2}$ lasers proved to be superior over scalpel surgery. It minimized post-operative swelling, minimal intraoperative trauma, site specific wound sterilization. This author suggested all these advantages are related to sealing of lymphatic vessels [30].

Amaral et, al. compared the effects of diode laser surgery to conventional scalpel surgery in the treatment of fibrous hyperplasia and concluded that diode lasers due to its high absorption by water and hemoglobin provides better results in oral surgical procedures [31].

Parker et, al. explained that as surgical cutting proceeds heat generated seals small blood vessels thereby reducing bleeding and odema and denaturated proteins within the tissue and plasma give rise to a surface zone of tenacious layer known as coagulum/char that protects the surgical wound from bacterial action, whereas scalpel wound doesn't cause any thermal damage but allow extravasation of blood and lymph causing marked inflammatory response resulting in swelling and odema [32].

Darcengelo et, al. reported that laser produce thermal changes in tissue thereby causing initial delay in healing response [33].

Normally diode lasers emit in continuous mode as compared to Nd:YAG, Er:YAG, emitting in pulsed mode. This means that during the pause between emission times, temperature inside the tissue may decrease (known as Thermal Relaxation Time- TRT), avoiding the risk of overheating of tissue and its subsequent damage. This inconvenience in diode lasers has been solved by introducing "chopped mode" where a rotating disk with some window (chopper) is put just after the device which permits to make an interruption of the beam allowing TRT to tissues.

Goharkay et, al. showed diode laser is very effective due to its coagulation ability and due to this property there is less thermal damage to the tissues adjacent to the site of injury and less chances of recurrence of premalignant lesions [34].

\section{Conclusion}

Treatment of premalignant lesions with the laser therapy is a reliable, reproducible technique which is associated with low complications and morbidity rates and can be practised on routine basis. As premalignant lesions have the tendency of recurrence and malignant transformation rates, tight follow-up and patient education to eliminate risk factors are recommended.

\section{References}

1. David CM, Gupta P. Lasers in Dentistry: A Review. Int J Adv Health Sci. 2015;2(8):7-13.

2. Shokrollahi K, Raymond E, Murison MSC. Lasers: Principles and Surgical Applications. Journal of Surgery. 2004;2(1):28-34.

3. Jerjes W, Hamdoon Z, Hopper C. CO2 lasers in the management of potentially malignant and malignant oral disorders. Head Neck Oncol. 2012;4:17.

4. Azma E, Safavi N. Diode Laser Application in Soft Tissue Oral Surgery. J Lasers Med Sci. 2013;4(4):206-211.

5. Panduric DG, Bago I, Zore IF. et al. Application of diode laser in oral and maxillofacial surgery In: Motamedi MH, ed. A Textbook of Advanced Oral and Maxillofacial Surgery. In Tech. 2013.

6. Coluzzi DJ. Fundamentals of dental lasers: Science and instruments. Dent Clin North Am. 2004;48(4):751-770.

7. Ehsan Azma, Nassimeh Safavi. Diode Laser Application in Soft Tissue Oral Surgery. J Lasers Med Sci. 2013; 4(4):206-211.

8. Ansari MA, Erfanzadeh M, Mohajerani E. Mechanisms of LaserTissue Interaction: II. Tissue Thermal Properties. J Lasers Med Sci 2013;4(3):99-106.

9. Mathur E, Sareen M, Dhaka P, Baghla P. Diode laser excision of oral benign lesions. J Lasers Med Sci. 2015;6(3):129-132. doi: 10.15171/ jlms.2015.07

10. Hamad SA, Naif JS, Abdullah MA. Effect of Diode Laser on Healing of Tooth Extraction Socket: An Experimental Study in Rabbits. J Maxillofac Oral Surg. 2016;15(3):308-314. DOI: 10.1007/s12663015-0842-x

11. Garg N, Verma S, Chadha M, Rastogi P. Use of carbon dioxide laser in oral soft tissue procedures. Natl J Maxillofac Surg. 2015; 6(1): 84-88. doi: 10.4103/0975-5950.168218

12. Gupta S, Kumar S. Lasers in Dentistry - An Overview. Trends Biomater. Artif Organs. 2011;25(3):119-123.

13. Kaur A, Misra N, Umapathy D, Shivakumar GC. Effectiveness of soft tissue diode laser in treatment of oral mucosal lesions. J Indian Acad Oral Med Radiol. 2017;29(3):238-241.

14. Ortega-Concepción D, Cano-Durán JA, Peña-Cardelles JF, ParedesRodríguez VM, González-Serrano J, López-Quiles J. The application of diode laser in the treatment of oral soft tissues lesions. A literature review. J Clin Exp Dent. 2017;9(7):925-928. doi: 10.4317/jced.53795

15. Vatsal Ramwala. Use of Diode Laser in the Management of Oral Leukoplakia - A Study of 10 Cases. IOSR-JDMS. 2016;15(7):81-85.

16. Kharadi UA, Onkar S, Birangane R, et al. Treatment of Oral Leukoplakia with Diode Laser: a Pilot Study on Indian Subjects. Asian Pac J Cancer Prev. 2015;16(18):8383-8386. 
17. Gabric D, Sušić M, Katanec D et al. Diode Laser and Conventional Technique for Soft Tissue Oral Surgery: A Pilot Study. RJPBCS. 2015;6(2):1913-16.

18. Sarkar S, KailasamS, Iyer VH. Effectiveness of Diode Laser and Er, Cr:YSGG Laser in the Treatment of Oral Leukoplakia-A Comparative Study. Dentistry. 2015;5:274. doi: 10.4172/2161-1122.1000274

19. Natekar M, Raghuveer HP, Panicker AG. A comparative evaluation: Oral leukoplakia surgical management using diode laser, CO2 laser, and cryosurgery. J Clin Exp Dent. 2017;9(6):779-784. doi: 10.4317/ jced.53602

20. Vohra F, Abdulaziz A, Al-Kheraif AA, et al. Efficacy of photodynamic therapy in the management of oral premalignant lesions. A systematic review. Photo diagnosis Photodyn Ther. 2015;12(1):150-159. doi: 10.1016/j.pdpdt.2014.10.001

21. Ishii J, Fujita K, Komori T. Laser surgery as a treatment for oral leukoplakia. Oral Oncol. 2003;39(8):759-769.

22.Singh KP, Mir Mohd GH, Jeelani U, Gupta S, Koul P, Kalsotra P. Carbon Dioxide Laser Surgery in Management of Oral Leukoplakia. International Journal of Contemporary Medical Research. 2016;3(12):3565-3567.

23. Horch HH, Gerlach KL, Schaefer HE. CO2 laser surgery of oral premalignant lesions. Int J Oral Maxillofac Surg. 1986;5(1):19-24.

24. Roodenburg JLN, Panders AK, Vermey A. CO2 laser surgery of oral leukoplakia. Oral Surg Oral Med Oral Path Oral Rad. 1991;71(6):670674.

25. Mogedas-Vegara A, Hueto-Madrid JA, Chimenos-Küstner E, Bescós-Atín C. The treatment of oral leukoplakia with the $\mathrm{CO} 2$ laser: A retrospective study of 65 patients. J Craniomaxillofac Surg. 2015;43(5):677-681. doi: $10.1016 / \mathrm{j} . j \mathrm{cms} .2015 .03 .011$
26. Jerjes W, Upile T, Hamdoon Z, et al. CO2 laser of oral dysplasia: clinicopathological features of recurrence and malignant transformation. Lasers Med Sci. 2012;27(1):169-179. doi: 10.1007/ s10103-011-0916-z

27. Del Corso G, Gissi DB, Tarsitano A, et al. Laser evaporation versus laser excision of oral leukoplakia: A retrospective study with longterm follow-up. J Craniomaxillofac Surg. 2015;43(6):763-738. doi: 10.1016/j.jcms.2015.04.009

28. Romanos G, Nentwig GH. Diode Laser (980 nm) in Oral and Maxillofacial Surgical Procedures: Clinical Observations Based on Clinical Applications. J Clin Laser Med Surg. 1999;17(5):193-197.

29. Monteiro LS, Mouzinho J, Azevedo A, Câmara MI, Martins MA, La Fuente JM. Treatment of epulis fissuratum with carbon dioxide laser in a patient with antithrombotic medication. Braz Dent J. 2012;23(1):7781.

30. Pick RM, Pecaro BC, Silberman CJ. The laser gingivectomy. The use of $\mathrm{CO} 2$ laser for the removal of phenytoin hyperplasia. J Periodontol. 1985;56(8):492-496.

31. Amaral MB, de Ávila JM, Abreu MH, Mesquita RA. Diode laser surgery versus scalpel surgery in the treatment of fibrous hyperplasia: a randomized clinical trial. Int J Oral Maxillofac Surg. 2015;44(11):13831389. doi: $10.1016 /$ j.ijom.2015.05.015

32. Parker S. Lasers and soft tissue: 'loose' soft tissue surgery. Br Dent J. 2007;202(4):185-191.

33. D’Arcangelo C, Di Nardo, Maio F, et al. A Preliminary Study of Healing of Diode Laser Versus Scalpel Incisions in Rat Oral Tissue: a Comparison of Clinical, Histological, and Immunohistochemical Results. Oral Surg Oral Med Oral Pathol Oral Radiol Endod. 2007;103(6):764-773.

34. Goharkhay K, Moritz A, Wilder-Smith P, et al. Effects on oral soft tissue produced by a diode laser in vitro. Lasers Surg Med. 1999;25(5): 401406. 